\title{
The Impact of Correction Center Formal Education Program on Offenders' Psychosocial Development the Case of Delo Mena, Goba and Sheshamene Correction Centers Primary Schools Bale-West Arsi Oromia South East Ethiopia
}

\author{
Gamachu Gishe Badasa (Assistant professor) ${ }^{1} \quad$ Abdurehman Gemeda $^{2} \quad$ Burash Elemo Geduda $^{3}$ \\ Esa Aliye Sedo ${ }^{1}$ Yealemwork Geshow \\ 1.College of Education and Behavioral Studies Department of Psychology Madda Walabu University \\ 2.MA Student in Leadership and Good governance at Ethiopian Public Service University \\ 3.Department of Adult Education and Community Development, College of Education and Behavioral Studies \\ Madda Walabu University \\ 4.College of Education and Behavioral Studies Department of Psychology Behder University \\ Corresponding Author: Gamachu Gishe. P. O. Box +251247
}

\begin{abstract}
The main objective of this study was to identify the impact of formal Correction education program on offenders' psychosocial development. For an in-depth investigation of Correction Center education, case study design was employed. The sampling technique used to select research participants was mainly purposive for the reason that it enables us to get individuals directly engaged in the practices of correction Centers primary schools. Thus, prisoners who are attending formal school, the respective head of selected Correction Centers, counselors, education coordinators, school principals, their teachers and education office heads were selected. Semi-structured interview guides were held with different participants to explore in-depth, rich, and seek to understand results of data that are unexpected. Besides, the researchers were selected three focus group meaning independently one group of experienced teachers and students at the respective Correction schools where one of the section criteria is homogeneity of people among many other inclusion rules. Data was transcribed and translated into English language for analysis. Correspondingly, findings relevant to the objective of the study was selected, Coded, organized, analyzed, presented, and discussed thematically in line with the objectives set. The study suggested that if facilities and an opportunity will be given for all who need it there is no doubt that correction center education would have positive impact on learners' psychosocial makeup. For instance, the school principal at Goba Correction was explained it as for the one who attend it seriously he/she can be effective. There are people who got a chance of education at their adulthood. Key informants assumed that these people do not have such opportunity if they were at home because the masses are youth and adult whose appropriate education modality via non-formal. So in this regard, Correction Center education is reducing illiteracy since the mainstream educational level is illiterate. More importantly, teachers at Goba Correction School were replied, as there were individuals who have continued learning until university and graduated from it and became employed in different organizations. It was found that those detainees on education program have been the first beneficiaries of parole and excuse given by government every New Year
\end{abstract}

Keywords: Bale-West Arsi, Impact, Correction Education, General Education, Rehabilitation

DOI: $10.7176 /$ PPAR/10-6-01

Publication date:June 30th 2020

\section{Background}

Incapacitation is a philosophy that has been used as plan for reducing crime by removing the offender from society and incarcerating them to prevent them from committing another crime (Visher, 1987 cited in Sumrall, Sumrall, Doss, 2016). According to incapacitation point of view, if an offender's freedom of movement is abridged temporarily or permanently and he/she is permanently supervised and kept under constant watch, such an offender will no longer is in a position to commit crime (Bohn and Haley, 1999, Obioha 2002, Danbazwu, 2011 cited in Esiri, 2016).

Consequently, Sumrall et al. (2016) have identified that there are two types incapacitation, collective and selective which are very different in terms of policies and outcomes on the behavioral modification of prisoners. Researchers asserted that unlike collective, selective incapacitation is an effective type of impressments as a crime control strategy by customizing sentencing for offenders. This strategy focuses on the individual offender. It is mainly useful for offenders who are considered to be a great risk to society and can be candidates for incarceration for an extended period of time (Sumrall et al., 2016). Again these scholars added that the plan for reducing crime by using selective incarceration is to identify offenders and to predict what they possibly may do in the future to society. This form of incapacitation is used to prevent the overcrowding of correction populations.

In the correction context, it means readying offenders to rejoin society, as useful and law-abiding members 
of the wider community (House of Commons, 2005). Another perspective is that people are sent to Correction to be reformed or rehabilitated (UN, 2005). It has a futuristic goal, which is to change the personality of the offender for an advantage in the future (Sumrall et al., 2016).

However, long ago many psychologists were against the rehabilitation philosophy model because corrections did not purposefully implement intervention package to replays offenders irrational behavior with healthy way of behaving and thinking (Sumrall et al., 2016). Similarly, others argued that what correction has persistently done to those who serve incarceration time is to give them many more problems than they had when they arrived (Inciardi, Martin, Butzin, Hooper, \& Harrison, 1997; Ortmann, 2000 cited in Gideon, Shoham, \& Weisburd, 2010).

Interestingly, Gideon et al.(2010) in their research with Israeli Correction population have explained how inmates perceive about rehabilitation philology. For them it might mean more vacations, better living conditions, the opportunity to earn money while incarcerated, and other privileges.

In general, when rehabilitative and reformative processes and programmes are adequately and meaningfully pursued and implemented for offender under conducive structural and environmental as well legal factors, that there may be decrease or significant reduction in recidivism (Esiri, 2016).

Deterrence is also another philosophy intended to discourage individuals who are in Correction from committing further crimes after they are released, as well as to deter those who might be inclined to commit crime (UN, 2005).

According to Hirschi's theory of social bond, if someone has a strong attachment with society they are less likely to go against the social norms or put the attachment at risk. Attachment can be to family, friends, religion, anything outside of themselves, which might be detached if the individual deviates from the norm (Hearn, 2010).

Leff and Warner (2006) in their research work on whether there is relationship between being connected to social network and mental illness suggested that patients' experienced reduced life opportunities, violated selfimage, poor coping competence and, ambivalent experiences were reported due to reduced social contacts.

Furthermore, according to Rosario et al. (2016) learning is described by inmate students as a means to acquire knowledge and competencies with practical applicability, thereby preparing them for life outside of Correction, and more immediately, helping them in the daily tasks and issues they face in Correction. In Norway the study showed that the Correction inmates are generally quite satisfied with the education quality, that they are highly motivated, and use appropriate learning strategies (Diseth et al., 2008). With regard to education and job opportunity after release the majority of offenders in past study noted that education improved their self-esteem, and having a chance at getting a job (Pettit \& Kroth, 2011).

Likewise, Duwe and Clark (2014) found that, obtaining a secondary degree in Correction significantly increased the odds of securing post-release employment. Thus, Rosario et al. (2016) noted that Correction educators must support prisoners who enroll in learning activities and prevent early drop out by designing new and creative Correction-based educational programmes.

Similarly, Skinner (2010) suggested that increased levels of education and employment opportunities reduced recidivism and improved reentry success. Lawbreakers who are tied to education program may develop social bonds to others and their community. Creating these relationships in work or education may strengthen their ties to society and decrease the likelihood of engaging in criminal behavior.

Again, Hearn (2010) conducted research whether there is relationship between individuals' commitment and the probability of taking part in problem behaviors. For example, someone who has invested time and energy into school or a career, would be less willing to take risk conversely, someone who had less investment within an institution would not feel the same level of loss if they were excluded.

All we can say, in Ethiopia alongside the benefit of education in producing skilled work force that will be able to contribute for its nation development, access to education is a fundamental human right and therefore, correction education has two fold purposes. For one hand, it reduces social inequality in education if the policy makers give much attention particularly to correction education, the education of Ethiopia aspire and have been aggressively implementing it for its social and political benefits. For other hand, education would built the fragile self-esteem of legal prisoners, develop hope on them and capacitate offenders to live save life with the society either being in the correction centers or when he/she back to the societies.

Therefore, in nutshell, the purpose main objective of this study is to identify the impact of the general formal Correction education program on offenders' psychosocial development the case of Delo Mena, Goba and Sheshamene Correction Centers Bale -West Arsi Oromia Regional State Ethiopia.

\section{Methods and materials \\ Description of Study areas}

Of the three schools selected for this study, Goba Correction Center School which has long life span than other is established since 1982. This school has 16 teachers of which 4 are female and the remaining are male. Besides, the school is teaching more than 300 students starting from grade 1 to $8^{\text {th }}$. Delo Mena Correction School is in Delo Mena Woreda at distance of $160 \mathrm{~km}$ from the zonal capital town Robe to South direction. In this Center, offenders 
who made crime at the neighboring Woredas like Harana Buluqi and Madda Walubu are referred to it for correction propose. It's year of establishment was 2008 and now teaching more than 100 inmates up to first primary cycle (1-4) by four teachers and all are males.

Sheshamene Correction Center which is found in West Arsi zone is a huge by intaking capacity; it has more than 2500 prisoners. This center is found in Sheshamene town to North direction near to the main road to the capital city of the country Addis Ababa. The school was opened in 2008 by teaching 1-4 grades. Then after, it was upgraded to full primary school in 2011. This school is undertaking its teaching learning process by three teachers hired by the town Education Office. The total number of students attending education is more than 350 , which is relatively big when it is compared with the number of Goba and Delo Mena Correction Schools students.

\section{Study design}

For an in-depth investigation of Correction Center education, case study design was employed.

\section{Sampling procedures}

The sampling technique used to select research participants was mainly purposive for the reason that it enables us to get individuals directly engaged in the practices of correction Centers primary schools. Thus, prisoners who are attending formal school, the respective head of selected Correction Centers, counselors, education coordinators, school principals, their teachers and education office heads were selected. Badasa, Sado and Melesu (2017) adopted similar strategies to sort participants before two years and thus, this work is part of our previous research work that part of it was published on African Journal of Social Work (AJOl).

\section{Data collection instruments}

\section{Semi-structure interview}

Semi-structured interview guides were held with different participants to explore in-depth, rich, and seek to understand results of data that are unexpected. Therefore, it was conducted with selected branch head of selected Centers, counselors, education coordinators, school principals, education office heads and zonal level Correction Center heads.

\section{Focus group discussion}

The researchers were selected three focus group meaning independently one group of experienced teachers and students at the respective Correction schools where one of the section criteria is homogeneity of people among many other inclusion rules.

In order to collect quality data from key informants, language is very important to avoid doubts or paraphrase the questions in case of inconsistency. To this end, participants were spoken by their mother tongue free. Moreover, the team of this research has rich experiences working with correction centers staff and prisoners as well alongside multilingual opportunity.

\section{Ethical Consideration}

In order to achieve this objective we strictly abided to the Ethical Principles of Psychologists and Code of Conduct amended and adopted by (APA, 2010). Thus, ethical approval letter was taken from Madda Walabu University Research, Community Engagement and Technology Transfer Vice President Office just to make possible data collection process.

\section{Methods of Data analysis}

The qualitative data obtained from key informants were transcribed and translated into English language for analysis. Correspondingly, findings relevant to the objective of the study was selected, coded, organized, analyzed, presented, and discussed thematically in line with the objectives set.

\section{Results and Discussion}

In principle, Correction centers education must be guaranteed to reduce recidivism because there is positive relationship between education and crime people made. Besides, it is expected that education can help prisoners being in the Center since it gives them many opportunity they lost before coming to Correction. More importantly, students' initial behavioral problems were also taken as baseline data. In general, therefore, these are the bench mark against which we evaluated the impact of education on learner/s.

For instance, the school principal at Goba Correction was explained it as for the one who attend it seriously he/she can be effective. Likewise, there are people who got a chance of education at their adulthood. She assumed that these people do not have such opportunity if they were at home because the masses are youth and adult whose appropriate education modality via non-formal. So in this regard, Correction Center education is reducing illiteracy since the mainstream educational level is illiterate. Moreover, according to Goba teachers there were individuals 
who are unable to write and read while they were detained in the center. Because of educational program, these people nowadays are capable of writing, reading and calculating well. Likewise, the prisoner who requests others to calculate his money at a time he sold his agricultural products before learnt how to do it by himself currently.

More importantly, teachers at Goba Correction School were replied, as there were individuals who have continued learning until university and graduated from it and became employed in different organizations. These key informants illustrated that one of their ex-student who was prisoner for 12 years in Correction Center is lecturer at Madda Walabu University. Not only this, other ex-prisoners were graduated from this university and became employed at different organizations.

Recognizing this adjudicated individuals also claim that they have no access to education particularly up on completion of grade eight either inside or outside the Center even though it is a need for these groups. No matter how in a very rarely condition some detainee have had an opportunity to learn out of the center from grade nine and currently join university. This found to be an asset for this individual even for psychological adjustment and other related behavioral change.

Ex-prisoners who is graduate of Madda Walabu University BSc in Computer Science replied as follows as far as the relationship between access to education and its impact on his psychosocial adjustments. According to him translated to its equivalent English language:

... I was around 16 years when I came in this Center for crime related to murder that led me 16 years of imprisonment. At that time I was a grade six student and unfortunately got a chance to continue my education in the center and at Goba Batu Tarara secondary school from grade 9-12. Since I had a great pledge for my education I felt happy and begun to perform effectively as everybody. Getting this occasion made me to attain my goal and could reduce emotional instability I might face.

This research team also interviewed counselor whether education given at the correction center he is working has an impact or not. The counselor explained the difference between educated prisoners and illiterate while delivering counseling; as it takes him sufficient time and session to deal with the uneducated offenders than their counterparts. He also explained how educated offenders easily adjust themselves with correction life circumstances compared to their counterparts.

Similarly, education coordinator at Sheshamene Correction reported that even though there are different obstacles emanated from this organization and other stakeholders that hamper students not to fully benefited from education program, considerable number of ex-offenders' and the present prisoners' behavioral problems were or are changed due to formal education given in the center.

For instance, one focus group participant who killed his wife and lifelong prisoner noted that

I started education from grade 1 and now I am attending $7^{\text {th }}$ grade. When I first joined the correction center I used to think about how to escape from Correction. But now, I have changed my mind. I am attending school as my friend who are at home.

The following quote was also reported by one prisoner who participated in focus group discussion at Delomena Correction center

... I used to think about taking revenge on those individuals who made me to be in Correction even though I am not guilty. Now in the education I got in the Correction Center, I came to understand that I was really guilty. I was charged of involving in deforestation. Now I have learnt what deforestation mean and its negative impact in environmental science subject.

The Bale Zone Correction centers administration vice head point out that those detainees on education program have been the first beneficiaries of parole and excuse given by government every New Year. In addition to this, this key informant suggested that many of students formed good attachment with the center being in the center via engaging him/herself to different social activities and business as well. Therefore, according to him this is the result of education the Center gave them.

Our finding is consistent with the research done by Skinner (2010) that education facilitates their ties to society and decrease the likelihood of engaging in criminal behavior. The current result also supported by Lochner and Moretti (2004) work that punishment is likely to be more costly for the more educated as incarceration implies time out of the labor market which is more costly for high earners. Our findings are strongly supported by past study that education improved their self-esteem, and having a chance at getting a job (Pettit \& Kroth, 2011).

\section{Conclusion and the way forward}

The study suggested that if facilities and an opportunity will be given for all who need it there is no doubt that correction center education would have positive impact on learners' psychosocial makeup. Since many of inmates are found at young age, the nations need adequate skilled labor forces who will scale up the conceived industrialization economic sector of our country. Therefore, investing on correction education reduce the likelihood of reoffending by implication the country will have law abiding citizen who promote smooth transition of democracy and culture of tolerance in their day to day interaction with diversified groups.

Therefore, giving education for offenders will help societies to live crime free environment. In addition to 
this, the attitude of the society toward correction center will be changed because majority of the societies assumed as societies in Corrections are morally harmed, badly treated during their life in jail. Thus, it is a good idea if the local communities help the school as they build religious institutions there.

To bring forward legal prisoners' teachers as a teachers have to be conditional while teaching because these students are not similar with other students since they need special treatment. Besides, there is a need to plan for restructuring organizational structure with respect to education to solve this problem the Commission and Oromia Education Bureau have big responsibility.

\section{Conflict of Interest}

We would like to notify that this article is our original work and there is no conflict of interest as far as this job is concerned.

\section{References}

APA. (2017). Ethical Principles of Psychologists and Code of Conduct. American Psychological Association

Badasa, G. G., Sado, I. A. \& Melesu, Y. G. (2017). Education Facilities and Motivation of Teachers \& Students at Correction Centers: The Case of Goba, Delomena and Sheshamene Oromia in Ethiopia. African Journal of Social Work Volume 7 Number 2

Diseth, A., Eikeland,O., Manger, T., \& Hetland, H. (2008). Education of Correction Inmates: Course experience, Motivation, and learning strategies as indicators of evaluation. Educational Research and Evaluation vol.14 no,3 201-214, DOI: 10.1080/13803610801956614

Duwe, G \& Clark, V. (2014). The Effects of Correction-Based Educational Programming on Recidivism and Employment. The Correction Journal 94: 454 DOI: 10.1177/0032885514548009

Esiri, O. M. (2016). The Upsurge of Recidivism and the Penitentiary Institutions in Nigeria. International Journal of Business and Social Science.

Gideon,L, Shoham, E, \& Weisburd, L. D. (2010). Changing Correction into a Therapeutic Milieu: Evidence from the Israeli National Rehabilitation Center for Correctioners. The Correction Journal 90 (2) 179-202

Hearn, N. (2010). Theory of Desistance. Internet Journal of Criminology.

House of Commons. (2005). Rehabilitation of Correctioners. Volume I Report, together with formal minutes. London.

Leff, J., \& Warner, R. (2006). Social inclusion of people with mental illness. NY University Press, Cambridge. http://dx.doi.org/10.1017/CBO9780511543937

Lochner, L., \& Moretti, E. (2004). The Effect of Education on Crime: Evidence from Correction Inmates, Arrests, and Self-Reports. The American Economic Review, Vol. 94, No. 1 pp. 155-189.

Pettit, D. M., \& Kroth, M. (2011). Educational services in Swedish Corrections: successful programs of academic and vocational teaching. Criminal Justice Studies: A Critical Journal of Crime, Law and Society. Vol. 24, No. 3, 215-226, DOI: 10.1080/1478601X.2011.592725

Quan-Baffour, P. K., \& Zawada, E. B. (2012). Education Programmes for Correction Inmates: Reward for Offences or Hope for a Better Life? J Sociology Soc Anth, 3(2): 73-81

Rosario, P., Nunez, C. J., Pereiro, J., Fuentes, S., Goeto, M., Cunha, J., \& Polydoro, S. (2016). Studying while doing time: understanding inmates' conceptions of learning. British Educational Research Journal Vol. 42, No. 1, February 2016, pp. 151-167. DOI: 10.1002/berj.3194.

Rose, D.C. (2003). Making the Grade in the Correction yard: who takes advantage of educational programming while incarcerated? Journal of Crime and Justice, 26: 2, 101-124, DOI;10.108010735648X.2003.9721184

Skinner, A. B. (2010). To what extent does Correctioners' mental illness undermine programming effectiveness? A thesis submitted in partial fulfillment of the requirements for the Doctor of Philosophy degree in Social Work in the Graduate College of The University of Iowa

Sumrall, R., Sumrall, W., \& Doss, A. D. (2016). A Review of Correctional Philosophies toward Reaffirming Rehabilitation as an Ohio Correctional Paradigm. International Journal of Business and Social Science Vol. 7. No. 5.

UN. (2005). Human Rights and Prisons. A Pocketbook of International Human Rights Standards for Prison Officials. New York and Geneva, United Nations 